\title{
INFLUÊNCIA DA NORMA DE DESEMPENHO NAS INSTALAÇÕES HIDRO-SANITÁRIAS PARA A PREVENÇÃO DE MANIFESTAÇÕES PATOLÓGICAS
}

\author{
VIEIRA, PAULO CEZAR CORRÊA \\ Professor \\ Instituto Federal do Amazonas \\ Amazonas; Brasil \\ correavieirapc@gmail.com
}

\author{
BARROS, LUANA THAINÁ OLIVEIRA \\ Discente - Engenharia Civil \\ Instituto Federal do Amazonas \\ Amazonas; Brasil \\ luanabarros9855@gmail.com
}

\section{RESUMO}

Sistemas hidro-sanitários funcionando plenamente garantem aos usuários dos edifícios as respostas esperadas ao acionarem dispositivos que disponibilizem a água e conduza efluentes para uma destinação final. Manifestações patológicas indicam mau funcionamento do sistema hidro-sanitário e, entrando em contato direto com o usuário, comprometem o bem estar físico físico e mental das pessoas. O trabalho teve por objetivo avaliar o cumprimento dos requisitos dos usuários, materializados na Norma de Desempenho, para a prevenção de manifestações patológicas em residências. Analisaram-se manifestações patológicas em instalações de edifícios, cujas causadas por projeto e execução em desacordo com a NBR-15575. Com a identificação e diagnóstico dos mecanismos de ocorrência das manifestações patológicas, foi possível aferir a importância do cumprimento normativo para que a edificação atenda as expectativas dos proprietários, as quais são muito bem exploradas pelas construtoras na venda.

Palavras-chave: patologias hidro-sanitárias, desempenho de edifícios, manifestações patológicas em instalações.

\section{ABSTRACT}

Hydro-sanitary systems operate fully guaranteed to building users as expected responses by triggering devices that provide water and carry effluents to a final destination. Pathological manifestations use malfunction of the sanitary system and, coming into direct contact with user, compromised or physical and mental well-being of people. The objective of this study was to evaluate or comply with user requirements, embodied in the Performance Standard, for the prevention of pathological manifestations in homes. Pathological manifestations in building installations, caused by design and execution in disagreement with NBR-15575, were analyzed. With the identification and diagnosis of pathological manifestation detections mechanisms, it was possible to determine the importance of regulatory compliance for building activation as expectations of requirements, such as which are very well explored by construction companies on sale.

Keywords: hydro-sanitary pathologies, building performances, pathological manifestations in installations.

\section{INTRODUÇÃO}

O mercado da construção civil historicamente apresenta ainda barreiras a transpor no que tange a qualidade da edificação residencial, o que gerou uma relação conturbada entre a cadeia produtiva e o consumidor usuário que tem na moradia própria um direito cristalino e objeto de sonho, principalmente nas camadas mais baixas da população. Não raro, obras residenciais oriundas da construção formal não atendem as expectativas dos proprietários, muitas vezes pela concorrência predatória que existe entre as empresas de construção, quando a corrida por menores preços de venda é resultado da redução do nível de qualidade funcional da moradia.

Com o rápido crescimento da indústria da construção civil entre os anos 2009 e 2014, houve uma preocupação do governo federal, indústria da construção e da sociedade em estabelecer requisitos de desempenho para as edificações residenciais de acordo com às expectativas dos usuários.

Em 19/07/2013 a ABNT publicou o conjunto normativo NBR-15575, composto pelas partes de 1 a 6, envolvendo todos os participantes do mercado habitacional amadurecendo as responsabilidades com a qualidade do imóvel e 
estabelecendo melhorias com responsabilidades na relação de consumo construtor x consumidor, ou seja, envolve construtor, projetista, incorporador, fabricante dos insumos e o usuário, havendo para todos incumbências definidas. Dentre as 06 (seis) partes que compõem a Norma de Desempenho, neste trabalho abordaremos a Parte 6 que trata das Instalações Hidro-sanitárias, um dos sistemas da edificação que mais apresenta manifestações patológicas, o que motivou o presente artigo.

Segundo o item 3.10 da NBR-15575-1, desempenho é o comportamento em uso de uma edificação e de seus sistemas, enquanto o item 3.17 indica que requisitos do usuário é o conjunto de necessidades do usuário da edificação habitacional e seus sistemas, tecnicamente estabelecidas na parte 1 desta norma.

Assim, a Norma de Desempenho, além de refletir os requisitos dos usuários e suas expectativas, tem papel fundamental na melhoria da qualidade do imóvel residencial, ainda que no seu nível mínimo de desempenho (M), embora constem da norma os níveis de desempenho intermediário (I) e superior (S).

Como a Norma de Desempenho (NBR-15575), não se aplica aos imóveis com projetos aprovados antes da sua entrada em vigor, bem como de obras que já estavam em andamento na mesma ocasião, há inúmeros registros de manifestações patológicas hidro-sanitárias que podem ser prevenidas em todos os projetos aprovados e obras em execução a partir de 19/07/2019, se forem acatadas as recomendações da referida norma, quanto aos requisitos do usuário.

Há uma relação entre a qualidade da edificação e o número de defeitos. Para Auchterlounie (2009), o número de defeitos é um indicador chave da qualidade que foi empregada na construção do imóvel pela indústria da construção civil. Harrison (1993) afirma que a qualidade está diretamente relacionada com o número de defeitos encontrados na propriedade.

Como os usuários entram em contato direto com o sistema hidrossanitário, observar os requisitos dos usuários na Norma de Desempenho é uma garantia de que a segurança e o conforto físico e mental dos mesmos estarão preservados.

\section{REVISÃO DA LITERATURA}

\subsection{Resistência mecânica dos sistemas hidrossanitários e das instalações}

A NBR-15575-6 estabelece, nesse requisito, que as tubulações devem resistir às solicitações mecânicas durante o uso. $\mathrm{O}$ critério 7.1.1 relativo às tubulações suspensas recomendam que os fixadores ou suportes das tubulações, aparentes ou não, assim como as próprias tubulações, devem resistir, sem entrar em colapso, a cinco vezes o peso próprio das tubulações cheias d'água para tubulações fixas no teto ou em outros elementos estruturais, bem como não podem apresentar deformações que excedam $0,5 \%$ do vão.

Como os tubos e conexões mais aplicados em sistemas de águas pluviais são de PVC, nas linhas de esgoto Série Normal ou Série Reforçada e fabricados conforme a NBR-5688/2018, os principais fabricantes nacionais indicam em seus catálogos técnicos e/ou manuais técnicos, a distância máxima correspondente a 10 x DN (diâmetro nominal) entre apoios em tubulações horizontais fixadas à laje ou qualquer outra estrutura.

Quando as tubulações forem submetidas a esforços dinâmicos significativos, esses esforços devem ser levados em consideração (NBR-15575/6 - item 7.1.1).

Segundo o Manual Técnico Tigre (2013), a experiência tem demonstrado que nos tubos com maior altura (a partir de 06 pavimentos), destinados à condução de águas pluviais ou esgotos, podem ocorrer pressões negativas (vácuo). Nesses casos a possibilidade de rompimento das tubulações é grande. Entre outras situações, o referido Manual aponta que se houver dimensionamento inadequado, a lâmina de água na calha encobre o(s) bocal(is) de saída e bloqueia a passagem do ar pelo interior do condutor vertical, resultando em sucção e, consequentemente, o colapso do tubo de PVC série normal.

Vale ressaltar que o vácuo acontece quando os diâmetros dos condutores verticais estão sub-dimensionados ou o número de condutores verticais está aquém da necessidade para que haja o escoamento em regime semi-afogado.

Segundo a publicação Air in pipelines da HR Wallingford (2005) nos escoamentos verticais de líquidos, quanto mais houver a passagem do ar pelo interior da tubulação, a água escoa em formato anelar como se fosse um filme colado à parede do tubo, enquanto o ar passa pelo setor central da seção transversal do tubo.

Para que não haja a pressão negativa no interior da tubulação, é indispensável que o ar esteja também no interior da tubulação.

\subsection{Tubulações hidrossanitárias e prevenção da propagação de chamas entre pavimentos}

As tubulações hidrossanitárias nos edifícios, entre outras, atravessam os pavimentos da cobertura ao térreo ou sub-solo, seja por meio de shafts ou simplesmente transpassando as lajes de concreto armado entre pavimentos.

O item 8.1 da NBR-15575-1 que trata das generalidades sobre a segurança contra incêndio, aponta que os requisitos relativos à segurança contra incêndio são pautados, entre outros, em dificultar a propagação do incêndio, reduzindo os 
danos ao meio ambiente e ao patrimônio. Assim, as tubulações devem ser objeto de cuidados especiais, de modo a não se transformarem em elementos de propagação do fogo no edifício.

O requisito 8.3 da NBR-15575-6 - Evitar propagação de chamas entre pavimentos - estabelece que quando as prumadas de esgoto sanitário e ventilação estiverem instaladas aparentes, fixadas em alvenaria ou no interior de dutos verticais (shafts), deverão ser constituídas de material não propagante de chama. Segundo o Instituto Brasileiro do PVC, como possui cloro em sua composição, trata-se de um material halógeno que não se inflama espontaneamente, que sua chama é auto-extinguível.

Quando a edificação está em condição de sinistro por incêndio, as tubulações hidro-sanitárias em PVC são consumidas pelo fogo, restando nas passagens de um pavimento para o outro as aberturas respectivas a cada tubo passante. Nessa condição, o fogo pode se propagar para os andares superiores através desses espaços. Como medida preventiva para o fechamento automático dessas passagens, consta a aplicação de pintura ablativa com o uso de lã de vidro, havendo a expansão desse material quando em contato com o fogo, vedando a abertura resultante do tubo consumido. Tal recomendação encontra respaldo na Coletânea de Manuais Técnicos de Bombeiros-48 (2006).

\subsection{Pressões máximas em tubulações de água fria}

O item 5.3.5 Pressões mínimas e máximas da ABNT NBR 5626/1998 determina que em condições dinâmicas (com escoamento), a pressão da água nos pontos de utilização deve ser estabelecida de modo a garantir a vazão de projeto e o bom funcionamento da peça de utilização e de aparelho sanitário. Em qualquer caso, a pressão não deve ser inferior a 10 $\mathrm{kPa}$, com exceção do ponto da caixa de descarga onde a pressão pode ser menor do que este valor, até um mínimo de 5 $\mathrm{kPa}$, e do ponto da válvula de descarga para bacia sanitária onde a pressão não deve ser inferior a $15 \mathrm{kPa}$.

A norma estipula também que em condições estáticas (sem escoamento), a pressão da água em qualquer ponto de utilização da rede predial de distribuição não deve ser superior a $400 \mathrm{kPa}$. A ocorrência de sobrepressões devidas a transientes hidráulicos deve ser considerada no dimensionamento das tubulações. Tais sobrepressões são admitidas, desde que não superem o valor de $200 \mathrm{kPa}$.

De acordo com a Norma de Desempenho - 15575-6 - As válvulas de descarga, metais de fechamento rápido e do tipo monocomando não devem provocar sobrepressões no fechamento superiores a 0,2 $\mathrm{MPa}$. Além disso, devem atender à pressão estática máxima estabelecida na ABNT NBR 5626.

A ABNT NBR 5626/1998 informa que quando uma válvula, torneira ou outro componente é fechado muito rapidamente, o fechamento é algumas vezes acompanhado por um claro ruído originado do fenômeno de transiente de pressão denominado golpe de aríete.

\subsection{Mau cheiro em instalações prediais de esgoto}

O requisito 15.5 da NBR 15575-6 - Ausência de odores provenientes da instalação de esgoto - determina que não é permitido o retorno de gases aos ambientes sanitários, devendo o sistema de esgoto ser projetado de forma a não permitir retrossifonagem ou quebra do fecho hídrico.

A retrossifonagem é definida pela ABNT NBR 15575-1 como o refluxo de água usada, proveniente de um reservatório, aparelho sanitário ou de qualquer outro recipiente para o interior de uma tubulação, devido à sua pressão ser inferior à atmosférica.

A ABNT NBR 8160/1999 conceitua o fecho hídrico como a camada líquida, de nível constante, que em um desconector veda a passagem dos gases.

O Manual Técnico da Tigre (2013) enfatiza que um dos componentes fundamentais para o perfeito funcionamento do sistema de esgoto, e que não pode ser esquecido, é a ventilação que caracteriza o conjunto de tubulações que permite a entrada de ar da atmosfera para o interior da instalação de esgoto. Desta forma, a ventilação protege os desconectores, impedindo o rompimento do fecho hídrico, ou seja, a falta do fecho hídrico no desconector ocasionado por uma eventual pressão negativa na instalação. Além disso, a ventilação permite a saída dos gases do esgoto para a atmosfera. O Manual ainda indica que as principais causas de mau cheiro em tubulações de esgoto são a ausência ou sistema de ventilação inadequado, ausência ou desconector inadequado, ausência ou vedação inadequada da saída do vaso sanitário, vedações ineficientes, caixas de passagem e de gordura com sistema ineficiente de vedação da tampa, ausência de plug no sifão da caixa sifonada.

\section{METODOLOGIA}

Para viabilizar a elaboração deste trabalho, foram selecionados casos reais constatados pelo autor durante o exercício de suas atividades profissionais ligadas à perícia em edificações e seus sistemas hidrossanitários, como engenheiro de aplicação em indústria do ramo de materiais de construção e também no exercício da perícia criminal, em que foram 
visitadas edificações residenciais para emissão de laudos relativos a danos contra o patrimônio, bem como laudos de perícias do setor de engenharia forense. Dentre os casos constatados, buscou-se elencar, pelo menos, quatro (04) em que as constatações realizadas durante as vistorias nesses imóveis tivessem relação direta com a inobservância de recomendações previstas na Norma de Desempenho (ABNT/ NBR-15575), para avaliação das patologias hidrosanitárias ou ainda riscos à segurança dos usuários de imóveis residenciais.

A acessibilidade e tipicidade da amostra foi fundamental para que a seleção ocorresse de forma intencional, sendo esta uma opção pelo uso de amostragem não-probabilística (RIZATTI JR.,2006).

\section{RESULTADOS E DISCUSSÃO}

Os dados foram coletados a partir das vistorias realizadas durante o exercício profissional do autor em visitas relativas às perícias extrajudiciais e perícias criminais, durante as quais foram constatadas inconformidades em relação aos requisitos da Norma de Desempenho. A amostra por conveniência tem sua razão em função do conhecimento prévio das condições encontradas nos sistemas hidro-sanitários dos edifícios vistoriados.

As inconformidades e respectivos imóveis constantes da amostra estão indicados na tabela 1.

Tabela 1: Relação das constatações de não-conformidade encontradas nos imóveis.

\begin{tabular}{c|c|c}
\hline Imóvel & Constatação & Pavimentos \\
\hline A & Ruptura em tubulação de águas pluviais & 18 \\
\hline B & Abertura em passagem de tubulações em caso de incêndio & 05 \\
\hline C & Sobrepressões em tubulação de água fria & 18 \\
\hline D & Mau cheiro em instalação de esgoto predial & 12 \\
\hline
\end{tabular}

\subsection{Ruptura em tubulação de águas pluviais}

A vistoria no Edifício A teve como objetivo apurar as causas de ruptura em condutor vertical de águas pluviais em desvio horizontal sobre o forro do apartamento de cobertura, durante uma chuva intensa, tendo como resultado a inundação de ambientes do imóvel sinistrado, resultando em danos materiais no revestimento do piso e partes inferiores de móveis modulados confeccionado com material do tipo madeirite.

A configuração da ruptura do tubo apresentou as características compatíveis com aquelas decorrentes de pressões negativas durante o escoamento, como pode ser observado na deformação do tubo que restou ovalizado.

O tubo utilizado originalmente no edifício, PVC esgoto série normal DN 100, com espessura de parede 1,8mm, não apresenta resistência suficiente para suportar eventuais sub-pressões quando utilizado em prédios com alturas correspondentes ao caso em evidência (18 pavimentos) quando deveriam ter sido especificados e aplicados tubos de PVC esgoto série reforçada, cuja espessura de parede é de 2,5mm, o que representa espessura 38,8\% superior aos tubos da série normal. Portanto, a segurança estrutural da tubulação, não está em acordo com o requisito 7.1 da ABNT/NBR15575-6/2013 em que as tubulações devem resistir às solicitações mecânicas durante o uso. A figura 1 mostra o estado de colapso do tubo, conforme constatado na vistoria realizada na edificação sinistrada.



Figura 1: Tubulação rompida por não resistir ao excesso de sub-pressões. 


\subsection{Abertura em passagens de tubulações em caso de incêndio}

Vistoria para realização em perícia criminal para apuração de causas motivadoras de incêndio aplásico em prédio com 05 (cinco) pavimentos, estando a área atingida pelo fogo compreendida entre os $2^{\circ}$ e $3^{\circ}$ pavimentos.

Durante os primeiros levantamentos, foram observadas aberturas correspondentes às passagens de tubulações de um pavimento para o imediatamente acima.

As prumadas em edifícios, quando executadas com materiais poliméricos, que atravessam os pisos de um pavimento para o outro precisam ser tratadas com material adequado para que a abertura que resulte do tubo consumido pelo fogo do pavimento inferior, se propague para o superior por meio de línguas de fogo.

O Edifício B, onde foi realizada a perícia, apresentou aberturas em lajes entre pavimentos, resultantes do espaço correspondente ao ocupado anteriormente pelo tubo consumido pelo fogo. A ABNT-NBR 15575-1, em seus requisitos 8.4 e 8.5 estabelece que há de ser previsto meio que dificulte a inflamação generalizada, tornando mais difícil a propagação do incêndio.

As instalações hidro-sanitárias, como sistema que contém prumadas que percorrem o edifício, podem ser um caminho natural de propagação do fogo em eventual sinistro. A figura 2 ilustra a propagação do fogo, de um pavimento para o superior do Edifício B, através de aberturas resultantes de tubulações consumidas pelo fogo, como pode ser verificado pelas impregnações fuliginosas nas paredes.

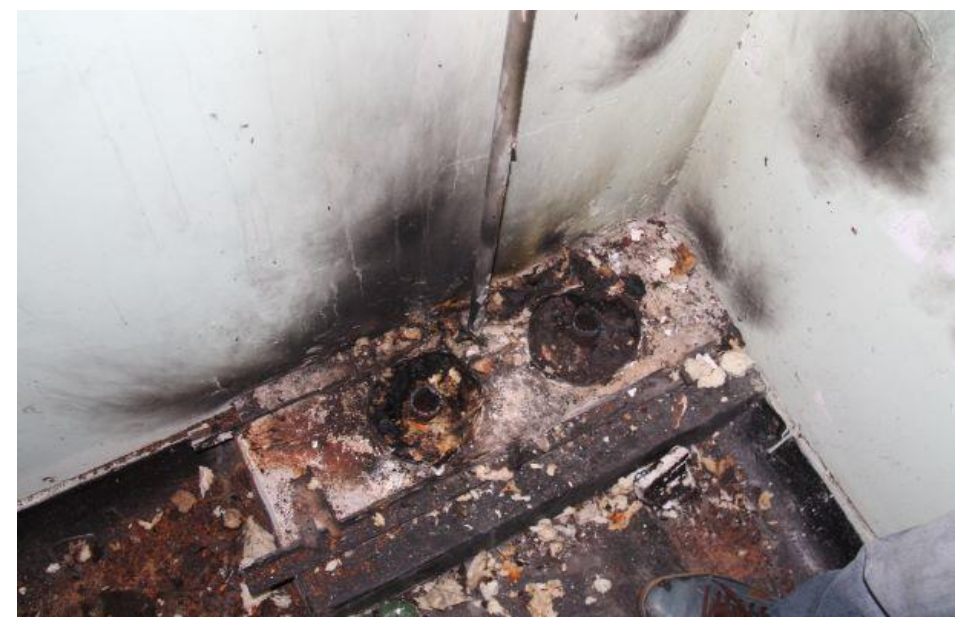

Figura 2: Abertura de tubulações com resquícios de fuligem causadas pela propagação do fogo entre a prumada do $2^{\circ} \mathrm{e}$ $3^{\circ}$ pavimento do imóvel B. Fonte: Os autores.

Com a selagem por meio de tinta ablativa e lã de rocha, é possível dificultar a propagação do fogo para andares mais consecutivos, pois com o aquecimento produzido pelo fogo o material aplicado se expande e naturalmente veda as aberturas que resultaram do tubo consumido pelo fogo. Tal procedimento vai de encontro aos requisitos 8.4 e 8.6 da ABNT-NBR-15575-1/2013, em que o tempo de resistência do material aplicado deve ser compatível com o do piso, de acordo com a NBR 6479.

\subsection{Sobre-pressões em tubulações de água fria}

Em vistoria no Edifício C para diagnosticar as causas de rupturas diversas em conexões de PVC soldáveis (NBR-5648) na instalação predial de água fria (figura 3), ocorridas em andares diversos, entre eles o $2^{\circ}, 3^{\circ}$ e $5^{\circ}$ pavimentos, constatou-se desobediência ao requisito 7.2 da NBR-15575 - Solicitações dinâmica dos sistemas hidrossanitários - e o critério 7.2.1 da mesma norma - Sobrepressão máxima no fechamento de válvulas e metais de fechamento rápido.

Com a utilização de manômetros com ponteiros de arraste instalados no pavimento sub-solo 1 (figura 4), verificaram-se pressões estáticas de $6 \mathrm{Kgf} / \mathrm{cm}^{2}$. Quando fechados os registros de esfera metálicos instalados em ramais próximos ao manômetro, constatou-se pressões de pico em $16 \mathrm{kgf} / \mathrm{cm}^{2}$, ultrapassando em $8,0 \mathrm{kgf} / \mathrm{cm}^{2}$ a pressão de serviço dos tubos e conexões de PVC soldáveis para água fria, estabelecido pela norma NBR-5648 em 7,5 Kgf/ $\mathrm{cm}^{2}$.

A figura 5 ilustra a pressão máxima registrada no manômetro, por meio do ponteiro de arraste, o que deu causa aos rompimentos no Edifício C, como consequência do não atendimento aos requisitos e critérios da NBR-15575/2013. 

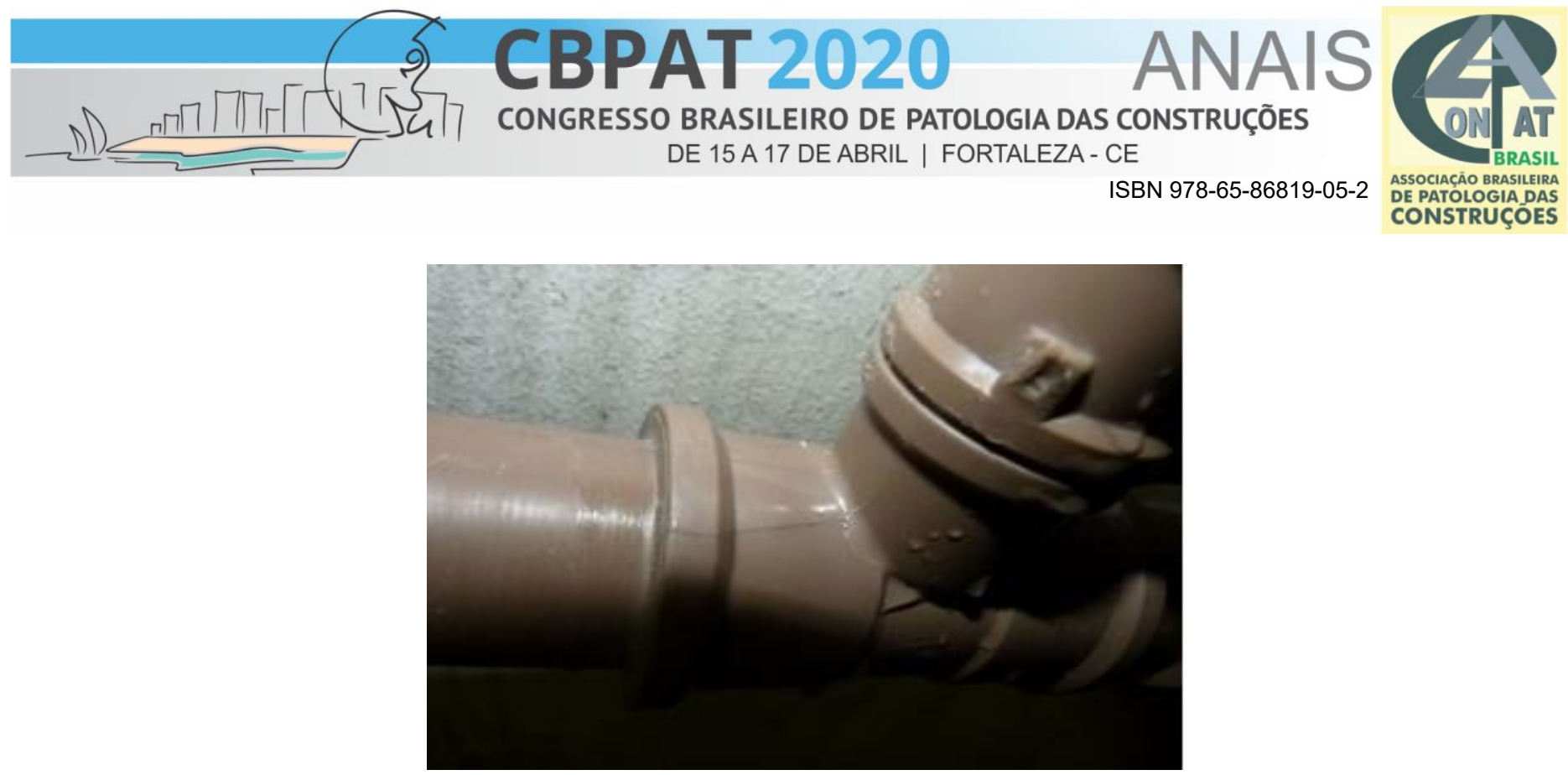

Figura 3: Tubo com ruptura em decorrência de pressão de serviço superior que a prevista em norma. Fonte: Arquivo pessoal dos autores

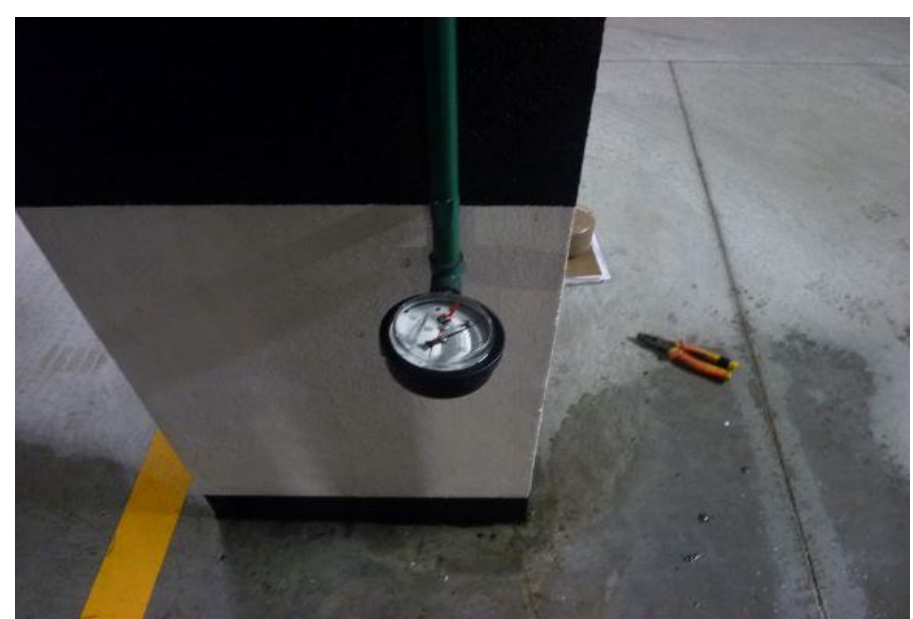

Figura 4: Manômetro instalado próximo às tubulações rompidas. Fonte: Arquivo pessoal dos autores

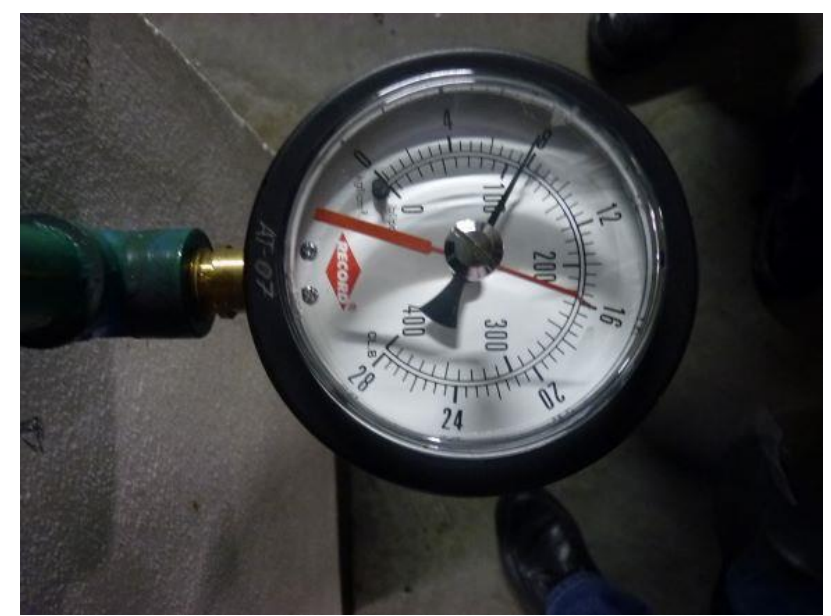

Figura 5: Manômetro apresentando pressão máxima de $16 \mathrm{kgf} / \mathrm{cm}^{2}$. Fonte: Arquivo pessoal dos autores 


\subsection{Mau cheiro em instalação predial de esgoto}

A perícia extra-judicial no imóvel D teve por objeto a identificação das causas de ocorrência de mau cheiro em banheiro da suíte master de um apartamento localizado no $6^{\circ}$ pavimento do edifício com 12 pavimentos.

A vistoria evidenciou que, das quatro suítes do apartamento, somente o banheiro da suíte master apresentava essa manifestação patológica.

Verificada a existência do fecho hídrico na caixa sifonada e vedações na fixação do vaso sanitário, passou-se a realização de teste para constatação de eventual quebra de fecho hídrico, o que foi possível por meio do acionamento da válvula de descarga do vaso sanitário e a visualização da superfície do líquido no interior da caixa sifonada (figura 6). Quando realizado o teste, houve turbulência e variações acentuadas na superfície da camada líquida, caracterizando a existência de vácuo parcial no ramal de esgoto daquele ambiente. O requisito 15.5 da NBR-15575-6/2013, ou seja, ausência de odores provenientes da instalação de esgoto, bem como o critério 15.5.1 da referida norma que consiste na exigência de que o sistema de esgoto sanitário deve ser projetado de forma a não permitir a retrossifonagem ou quebra do fecho hídrico. Neste caso configura-se a desobediência à NBR-15575-6/2013, bem como a própria NBR-8160/1999 - Sistemas prediais de esgoto sanitário.

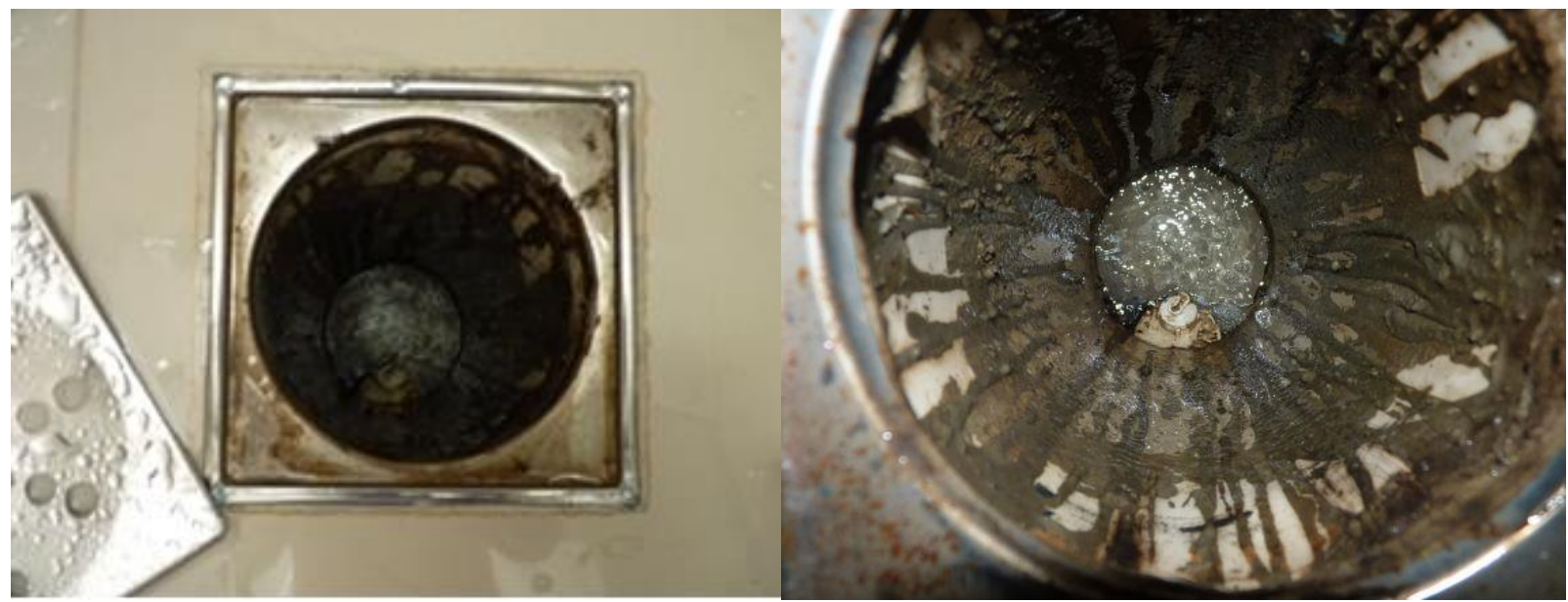

Figura 6: Variação na superfície do líquido na caixa sifonada.

Fonte: Arquivo pessoal dos autores

\section{CONCLUSÃO}

Com a identificação e diagnóstico dos mecanismos de ocorrência das manifestações patológicas e riscos à preservação da segurança de moradores, foi possível aferir a importância do cumprimento normativo para que a edifícação atenda as expectativas dos proprietários, as quais são muito bem exploradas pelas construtoras na venda.

A Norma de Desempenho (NBR-15575-6/2013) tem a sua base de requisitos em função da satisfação, conforto, segurança e bem-estar dos usuários dos imóveis residenciais. A observação dos seus requisitos e critérios garante a prevenção de manifestações patológicas nos sistemas hidro-sanitários e atende aos requisitos de desempenho baseados nas expectativas dos usuários. As constatações obtidas nas vistorias realizadas, embora em edificaões anteriores à vigência da Norma de Desempenho, corroboram significativamente para demonstrar que o não atendimento a tais requisitos e critérios resulta em transtornos aos moradores e proprietários, indo além dos dissabores ao bem estar das pessoas como também representando custos com eventuais ações de manutenções corretivas, caso tais manifestações ocorram após o prazo de garantia legal das construtoras.

\section{REFERÊNCIAS}

ASSOCIAÇÃO BRASILEIRA DE NORMAS TÉCNICAS. NBR 15575-1: Edificações habitacionais - Desempenho. Parte 1: Requisitos gerais. Rio de Janeiro, 2013. 
ASSOCIAÇÃO BRASILEIRA DE NORMAS TÉCNICAS. NBR 15575-1: Edificações habitacionais - Desempenho. Parte 6: Requisitos para os sistemas hidrossanitários. Rio de Janeiro, 2013.

ASSOCIAÇÃO BRASILEIRA DE NORMAS TÉCNICAS. NBR 5626: Instalação predial de água fria. Rio de Janeiro, 1998.

ASSOCIAÇÃO BRASILEIRA DE NORMAS TÉCNICAS. NBR 5648: Sistemas prediais de água fria - Tubos e conexões de PVC 6,3, PN 750 kPa, com junta soldável - Requisitos. Rio de Janeiro, 1999.

ASSOCIAÇÃO BRASILEIRA DE NORMAS TÉCNICAS. NBR 8160: Sistemas prediais de esgoto sanitário Projeto e Execução. Rio de Janeiro, 1999.

ASSOCIAÇÃO BRASILEIRA DE NORMAS TÉCNICAS. NBR 5688: Tubos e conexões de PVC-U para sistemas prediais de água pluvial, esgoto sanitário e ventilação - Requisitos. Rio de Janeiro, 2018.

ASSOCIAÇÃO BRASILEIRA DE NORMAS TÉCNICAS. NBR 6479: Portas e vedadores - Determinação da resistência ao fogo. Rio de Janeiro, 1992.

AUCHTERLOUNIE, T., 2009, "Recurring quality issues in the UK private house building industry, Structural Survey, v. 27, n. 3, pp. $241-251$.

CORPO DE BOMBEIROS DA POLÍCIA MILITAR DO ESTADO DE SÃO PAULO. Coletânea de Manuais Técnicos de Bombeiros: Segurança contra incêndio nas edificações e áreas de risco. 1. ed. 8. vol. São Paulo, 2006.

HARRISON, Andrew , Housing Quality Indicators, DEGW plc, United Kingdom. Disponível em http://www.housingcorp.gov.uk (Acesso em Abril de 2015).

HR WALLINGFORD Ltd. Air problems in pipelines - A design manual. Wallingford, UK, 2005

RIZATTI JR., G., 2006, Componentes Estratégicos para Categorias de Análise do Sistema de Gestão Ambiental. Tese (Doutorado), UFSC, Florianópolis, SC, Brasil.

TIGRE S.A. - TUBOS E CONEXÕES. Manual Técnico da Tigre - Orientações técnicas sobre instalações hidráulicas prediais. 5. ed. Joinville - SC, 2013. 